\title{
Possibilidades de abordagens da Educação Ambiental no cinema: Um diálogo crítico a partir do filme "Rio"
}

Possibilities of Environmental Education approaches in the cinema: A critical dialogue from the film "Rio"

Posibilidades de abordajes de la Educación Ambiental en el cine: Un diálogo crítico a partir de la película "Río"

\author{
Laise Vieira Gonçalves \\ Doutoranda, UNESP, Brasil. \\ laise.vieira@unesp.br
}

\section{Angélica Aparecida Amarante Terra Professora Doutoranda, IFSudeste-MG, Brasil. angelica.terra@ifsudestemg.edu.br}

Antonio Fernandes Nascimento Junior Professor Doutor, UFLA, Brasil. toni_nascimento@yahoo.com.br 


\title{
RESUMO
}

É sabido que, desde a Revolução Industrial, o mundo tem sofrido problemas ambientais por consequência de urbanizações desenfreadas que provocam exclusão social deslocando a população rural do campo para a cidade, desmatando e substituindo homens por máquinas. Desse modo, se torna fundamental compreender os contextos socioambientais que perpassam nossa sociedade bem como promover o despertar de uma consciência crítica que possibilite transformar as realidades a nossa volta. Neste sentido, o objetivo deste trabalho é analisar, de maneira crítica, as possibilidades de abordagens da educação ambiental a partir do filme Rio (2011) no que tange a realidade ambiental brasileira. O filme é uma animação baseada nas aventuras de um casal de ararinhas azuis e discute a biopirataria, a extinção de espécies a preservação e o cuidado com o meio ambiente. Para tal foram feitas seleções de cenas as quais possibilitaram uma discussão acerca das possibilidades de abordagens da educação ambiental de maneira crítica. Foi possível perceber que o Filme Rio apresenta o predomínio de uma visão conservacionista da educação ambiental sendo necessária uma análise mais social do filme para a construção de uma visão crítica da educação ambiental uma vez que esta visão tem o papel de entender o ambiente em sua totalidade incluindo reflexões acerca das questões políticas, econômicas, éticas, culturais e sociais que envolvem o ambiente. Ao mesmo tempo, tal análise não inviabiliza a utilização do filme Rio no ensino da educação ambiental podendo ampliar as possibilidades de abordagens numa perspectiva mais crítica.

PALAVRAS-CHAVE: Educação Ambiental; Cinema e Ensino; Filme Rio.

\begin{abstract}
It is well known that since the Industrial Revolution the world has suffered environmental problems as a result of unbridled urbanization that provokes social exclusion, displacing the rural population from the countryside to the city, deforesting and replacing men with machines. In this way, it becomes fundamental to understand the socioenvironmental contexts that permeate our society as well as to promote the awakening of a critical conscience that makes it possible to transform the realities around us. In this sense, the objective of this work is to analyze, critically, the possibilities of approaches of environmental education from the film Rio (2011) regarding the Brazilian environmental reality. The film is an animation based on the adventures of a pair of blue macaws and discusses biopiracy, the extinction of species preservation and care for the environment. For this purpose, selections of scenes were made which enabled a discussion about the possibilities of environmental education approaches in a critical way. It was possible to notice that Rio Film presents the predominance of a conservationist view of environmental education, requiring a more social analysis of the film to construct a critical view of environmental education since this vision has the role of understanding the environment in its entirety including reflections on the political, economic, ethical, cultural and social issues surrounding the environment. At the same time, such an analysis does not impair the use of the Rio film in the teaching of environmental education, and may increase the possibilities of approaches in a more critical perspective.
\end{abstract}

\section{RESUMEN}

Es sabido que, desde la Revolución Industrial, el mundo ha sufrido problemas ambientales como consecuencia de urbanizaciones desenfrenadas que provocan exclusión social desplazando a la población rural del campo a la ciudad, deforestando y sustituyendo hombres por máquinas. De ese modo, se vuelve fundamental comprender los contextos socioambientales que atraviesan nuestra sociedad así como promover el despertar de una conciencia crítica que posibilite transformar las realidades a nuestro alrededor. En este sentido, el objetivo de este trabajo es analizar, de manera crítica, las posibilidades de abordajes de la educación ambiental a partir de la película Río (2011) en lo que se refiere a la realidad ambiental brasileña. La película es una animación basada en las aventuras de una pareja de araritas azules y discute la biopiratería, la extinción de especies a la preservación y el cuidado con el medio ambiente. Para ello se realizaron selecciones de escenas que posibilitaron una discusión acerca de las posibilidades de abordajes de la educación ambiental de manera crítica. Fue posible percibir que la Película Rio presenta el predominio de una visión conservacionista de la educación ambiental siendo necesaria un análisis más social del filme para la construcción de una visión crítica de la educación ambiental ya que esta visión tiene el papel de entender el ambiente en su totalidad incluyendo reflexiones sobre las cuestiones políticas, económicas, éticas, culturales y sociales que involucran el ambiente. Al mismo tiempo, tal análisis no inviabiliza la utilización de la película Río en la enseñanza de la educación ambiental, pudiendo ampliar las posibilidades de abordajes desde una perspectiva más crítica.

PALABRAS CLAVE: Educación ambiental. Cine y Enseñanza. Película Río I. 


\section{INTRODUÇÃO}

Os filmes produzidos, com foco na temática ambiental, refletem um conjunto de valores e conceitos relacionados às visões de mundo, sendo possível relacioná-los com as diferentes concepções de Educação Ambiental (FERREIRA, 2011). E, mais especificamente relacionado ao desenho animado, o mesmo contempla uma abordagem lúdica podendo ser um valioso instrumento para favorecer o processo ensino-aprendizagem (GOMES et al, 2012).

Ainda em consonância com Gomes (idem), a educação ambiental é um processo participativo a partir do qual o indivíduo interage com o meio onde vive, de forma que as suas atitudes estejam voltadas para a conquista de um meio ambiente equilibrado. Neste sentido, ensinar a educação ambiental é construir conceitos, valores, atitudes, compreender o mundo, modificá-lo e desse modo (re)construí-lo, ou seja, a educação ambiental é uma construção e não apenas a transferência de um conhecimento estável e descontextualizado. Assim, cada vez mais percebemos a necessidade de se repensar o atual modelo educacional de ensino a fim de contribuir para superação de um ensino descontextualizado, fragmentado e que forma alunos não críticos e pouco autônomos. Além disso, é necessário refletir sobre a educação como uma prática social que forma cidadãos, baseando-se na justiça e na igualdade social.

Para a autora Tozoni-Reis (2008) a pesquisa em educação ambiental tem como principal objetivo 'produzir conhecimentos sobre processos educativos críticos com compromisso de transformação das relações sociais e ambientais na perspectiva da emancipação e de que é preciso buscar qualidades dos processos educativos para compreendê-los'. Assim, a criação de instrumentos que permitam aos diferentes atores da educação ambiental o reconhecimento das características das diferentes propostas educativas, bem como a identificação de elementos importantes para a construção de práticas com características mais críticas é uma das possibilidades de pesquisa na área (SILVA; CAMPINA, 2011).

Desse modo, a educação ambiental deve priorizar a formação de cidadãos capazes de conhecer o ambiente em que vivem para que possam transformá-lo participando ativamente das problemáticas relacionadas à ciência. Também é necessário que os conteúdos façam sentido para os sujeitos no processo de ensino-aprendizagem, contribuindo para esses compreendam os fenômenos da realidade em sua totalidade.

Nesta perspectiva, o objetivo deste artigo é analisar, de maneira crítica, as possibilidades de abordagens dos conteúdos da educação ambiental a partir do filme Rio (2011) no que tange a realidade ambiental brasileira.

\section{Cinema e Educação Ambiental}

Cada dia mais as imagens fazem parte da vida e do cotidiano das pessoas caracterizando-se como um meio de informação e formação constante. Segundo Medeiros (2012) as imagens em movimento se destacam, neste universo, como uma das grandes responsáveis por observações e experiências ao quais nos dão base e nos apoiamos para construir nossos saberes e conhecimentos sobre um mundo em constante transformação. Em consonância com Barros et al. (2013), o cinema 'reconstrói a vida social, expressa práticas sociais, modos de pensar, valores, tensões, comportamentos e visões de mundo de uma determinada sociedade em um 
determinado momento histórico'. Desse modo, o cinema nos leva a ver o mundo e o nosso cotidiano de uma forma mais ampla e profunda (NASCIMENTO JUNIOR et al, 2016).

O cinema se propagou pelo mundo chegando também ao campo da educação e abrindo caminhos para pensá-lo como um recurso pedagógico. No Brasil, ele está presente neste campo desde o início da década de 1930 com a inserção dos "livros de imagens luminosas" e com a criação do Instituto Nacional de Cinema Educativo no final da mesma década (DUARTE; GONÇALVES, 2014). Hoje, o cinema está muito presente no cotidiano dos alunos e, por isso, não pode ser deixado de lado no processo educacional (KLAMMER et al. 2006).

Nesta perspectiva, em 2014 foi criada a lei 13.006, que altera a Lei de Diretrizes e Bases da Educação Nacional - LDB de 1996, tornando o cinema nacional obrigatório nas escolas brasileiras integrando a exibição de filmes de produção nacional, que constitui componente curricular complementar integrado à proposta pedagógica da escola (BRASIL, 2014).

Para Nascimento Junior et al (2016), o cinema se mostra como um recurso com grande potencialidade para contextualizar e problematizar os conhecimentos das diferentes áreas uma vez que traz diferentes situações do cotidiano dos alunos.

O filme Rio trata de um tema bastante sensível e importante, que é o contrabando de animais silvestres, triste realidade que assola a fauna brasileira. Ele debate a ecologia por meio da extinção de espécies e da preservação e cuidado com o meio ambiente. Mas, também é preciso pensar em qual tendência da educação ambiental o filme se concentra, quais contextos ambientais são apresentados e qual consciência ambiental é (ou pode ser) despertada.

Nesse sentido, consideramos que se faz relevante investigar a abordagem dos conteúdos da educação ambiental e sua associação com o cinema na prática pedagógica, sendo importante compreender como estes filmes podem contribuir na construção de conhecimentos que envolvem a educação ambiental, contemplando uma formação cidadã que de fato possibilite a compreensão e transformação da realidade ambiental e social.

\section{METODOLOGIA}

A utilização de filmes como recurso pedagógico pode facilitar o processo ensino aprendizagem, pois, de acordo com abordagem sócio interacionista, o público pode se identificar com os personagens compartilhando suas ações e emoções, expressas na linguagem do audiovisual (SERRA; ARROIO, 2008).

$E$, além da popularidade de filmes entre os jovens, os problemas ambientais são objetos de muitos estudos e de várias discussões nas últimas décadas (SERRA; ARROIO, 2008). Por isso, propomos neste trabalho a análise de filmes com base na perspectiva vygostkiana (Vygotsky, 1978) para contextualizar conteúdos da educação ambiental expressos no filme. A análise foi direcionada por meio da decupagem, descrição e discussão de cenas/situações presentes no filme buscando a compreensão das abordagens da educação ambiental expressas por ele. Assim, partindo da análise de cenas do filme, foram destacados elementos da trama que será de fundamental importância para sustentar o seu potencial para o ensino da Educação Ambiental. Todas as figuras/cenas aqui apresentadas tem como fonte a decupagem do filme feita pelos autores do trabalho. 


\section{RESULTADOS E DISCUSSÃO}

A trama se inicia com a imagem da orla do Rio de Janeiro juntamente com o Pão de Açúcar e a vegetação florestal, seguido do canto e dança de muitas aves no ambiente da floresta ao som da música 'Favo de mel' que concorreu ao óscar 2012.

\section{Figura 1: Cena inicial mostrando as aves e a mata atlântica ao som da música} Favo de mel.

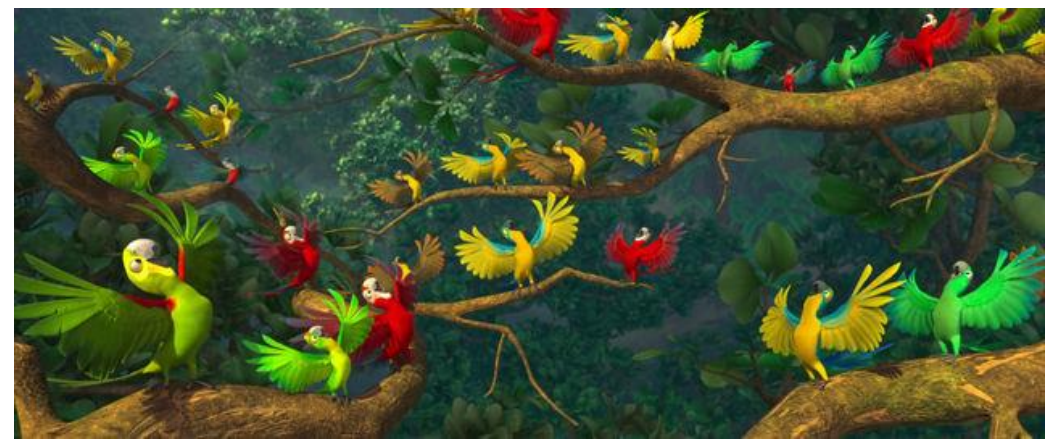

Fonte: Decupagem feita pelos autores, 2018.

Estas cenas iniciais mostram uma floresta do Rio de Janeiro, possivelmente na Floresta da Tijuca que faz parte do bioma da Mata Atlântica. Como retratado no filme, uma enorme quantidade de aves segue feliz, cantando, numa perfeita harmonia. No entanto, sabemos que este ambiente foi amplamente devastado por meio do crescimento da cidade do Rio de Janeiro e, até hoje, os animais e plantas sofrem com a falta de espaço, a interferência humana e os crimes ambientais praticados naquela região que diminui, cada vez mais, estas populações.

Os animais são embalados, neste momento, ao som da música 'Favo de mel' com assovios dos passarinhos e, aos poucos, são introduzidos o som do agogô, da cuíca, do surdo e da escola de samba. A música foi criada em 2011 por Carlinhos Brown, Sérgio Mendes, John Powell, Mikael Mutti e Siedah Garrett e interpretada por Jesse Eisenberg, Jamie Foxx, Anne Hathaway, George Lopez e William. Ela é um samba de fundo de quintal e reitera a brasilidade anunciando a alegria, a esperança e o amor à vida que há no país, como podemos ver na letra apresentada a seguir:

\begin{tabular}{|l|l|l|}
\hline E aí, meu rio! & De encontrar o céu (o céu) & Rei da capoeira \\
Vou levando a alegria & A gente se ama & Eira, eira, eira, eira, eira! \\
Junto carrego o amor & E a vida é um favo de mel & Minha asa é maneira (Pedro-asa- \\
Dia de festa, salve a floresta & Todas as aves do mundo (oohh) & maneira) \\
Hoje tem baile onde for & Que vida fenomenal (oohh) & Aqui todos amam o samba (adoram \\
o samba) \\
O soje dia está lindo & A lua, estrelas (oohh) & No coração ele está (nisso eu sou o \\
Quando o amigo alto cantou & Violas singelas (oohh) & bamba) \\
Toda a floresta acordou & Vivemos pro carnaval & Vida e amor, beleza e calor (ha) \\
Dentro de mim há esperança & Eaí, meu Rio! & O sonho está vivo no Rio, no Rio \\
Quero aprender a voar & Amamos a vida na mata & (aha) \\
Esse é meu sonho desde criança & Livre e selvagem é sim & É esse o lugar (o lugar) \\
Venha comigo, levanta, é hora & Vamos ficar este é nosso lar & Magia, encanto \\
De encontrar o céu (o céu) & Sinta a magia no Rio, no Rio & Somente aqui vai achar. \\
A gente se ama & É só prazer & \\
E a vida é um favo de mel & Beleza, feitiço & \\
\hline
\end{tabular}


Levanta, é hora

O samba retrata os acontecimentos de nossa história de uma forma criativa e original. Por meio dele se canta uma "outra" história, através da qual é possível conhecer o modo de vida dos povos que aqui se fixou, bem como seus costumes e valores, suas tradições, sua maneira própria de ser livre e de se fazer respeitar a partir de características de pertencimento que vão constituindo a identidade cultural de cada grupo responsável pela constituição do povo brasileiro (NOGUEIRA, 2006).

Em consonância com Alves (1976) apud Nogueira (2006, p.2), 'o samba é um caminho que possibilita uma leitura crítica para conhecermos um pouco mais as peculiaridades desses povos' sendo o samba 'uma evocação de um passado integrado na história do Brasil'. E, como disse Noel Rosa: "O samba, a prontidão e outras bossas/ São nossas coisas, são coisas nossas" e, por isso mesmo, é fundamental reconhecê-las.

No entanto, nenhum desses elementos é explorado no filme. A música inicial dá um tom harmônico e animador para o filme, mas acaba por não problematizar as questões políticas, culturais, socioambientais que envolvem a cidade do Rio de Janeiro. Ela acaba por trazer somente a visão do Rio de Janeiro como a cidade maravilhosa, com um espírito de festa e amor à natureza retratando, parcialmente, a realidade do Rio de Janeiro e contribuindo para reforçar estereótipos já existentes sobre a 'cidade maravilhosa'.

A animação mostra, ainda, um Brasil inclinado à alegria, apesar de suas mazelas sociais, reduz a criminalidade do país à população que vive em favelas e apresenta a questão do tráfico de animais silvestres de maneira superficial, não discutindo as questões econômicas, políticas e sociais que envolvem este 'mundo' do crime. Esse recorte impede uma visão, em sua totalidade, das questões que envolvem o ambiente da cidade do Rio de Janeiro.

Em meio à dança inicial a plenitude é quebrada e um verdadeiro caos é instalado. De repente, os pássaros começam a serem presos em gaiolas e armadilhas sendo levados até um avião que decola rapidamente sem deixar rastros. Dentre estes animais está Blu, uma ararinha azul que passa a viver em Minesota-EUA e, posteriormente, retorna ao Brasil.

Figura 2: Blue sendo capturado e levado da floresta

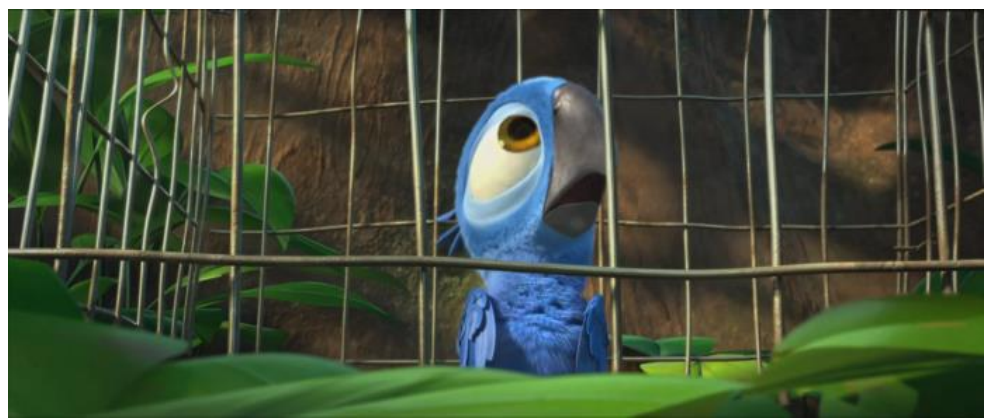

Fonte: Decupagem feita pelos autores, 2018.

Em seguida, os negociadores se encontram para concretizar o comércio das aves. Ao esconder os negociadores e mostrar somente a sombra de duas mãos, uma entregando e a outra recebendo o dinheiro, confirma-se um ato de compra e venda ilegal de animais silvestres. Nestas cenas o vilão é apresentado na forma de ganância, suborno, propina ou o jeitinho brasileiro, que é comentado nos estudos de DaMatta (1984) apud Lisboa (2012). 
Figura 3: Encontro dos negociadores para concretizar o tráfico de animais silvestres, tema central do filme.

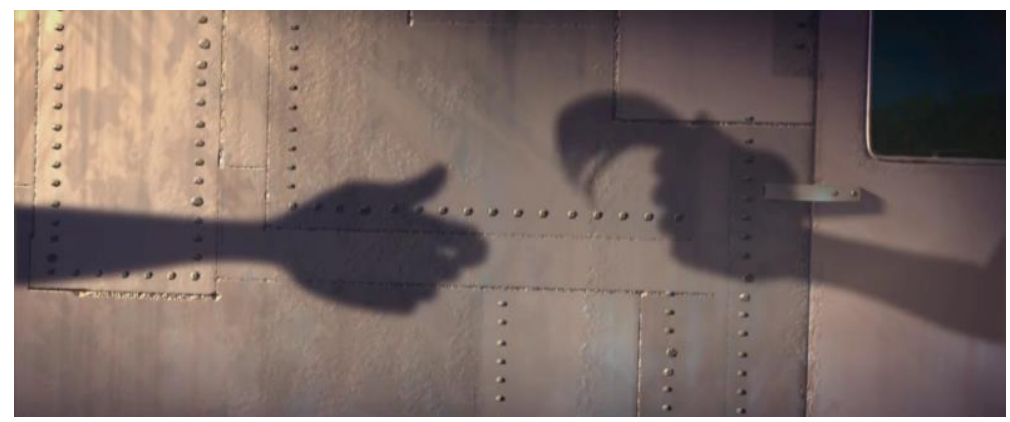

Fonte: Decupagem feita pelos autores, 2018.

Em outro momento, a questão do samba volta a se fazer presente no filme quando a personagem Linda, juntamente com Túlio, está em busca do casal de ararinhas e acabam por adentrarem no Sambódromo da Marques de Sapucaí durante um desfile de escola de samba. Neste momento, a personagem Linda, de nacionalidade Americana e que nunca havia participado de um desfile de escola de samba, se vê obrigada a perpassar pelas Alas em busca das ararinhas azuis. Ao avistar as ararinhas ela começa a percorrer o circuito do Sambódromo, pulando obstáculos, subindo e descendo em carro alegórico. Aos poucos Linda vai 'requebrando' durante o trajeto e, ao final dele, já está completamente engajada no 'samba'.

Figura 4: Linda tentando se equilibrar sai requebrando em busca de Blue no sambódromo

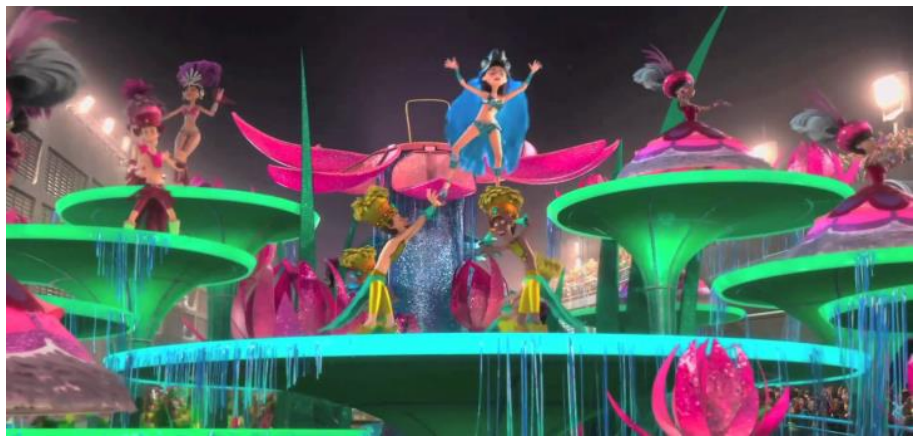

Fonte: Decupagem feita pelos autores, 2018.

Neste contexto, podemos perceber que o ato de sambar acaba por ser reduzido ao ato de requebrar, como se fosse algo muito simples e de fácil aprendizado não necessitando de técnicas mais especializadas. Mais uma vez o filme passa aos telespectadores uma simplificação da realidade contribuindo para a construção de uma visão simplista e equivocada do samba, gênero musical que faz parte da vida, da subjetividade dos cariocas e dos brasileiros sendo uma das principais manifestações populares brasileira que envolve uma construção bastante complexa. É possível perceber no filme um apelo imaginário sobre o carnaval que acaba por reforçar uma realidade estigmatizada do que é esta festa brasileira. Na cena abaixo Túlio apresenta um pouco da 'cidade maravilhosa' para Linda. Ao centro temos o estereótipo idealizado da mulher tipicamente brasileira que seria a mulata curvilínea com samba no pé e, muitas vezes, estereotipada como de sexo fácil. Linda fica espantada com a 'nudez' da brasileira. 
Figura 5: Estereótipo da mulher brasileira - mulata com samba no pé

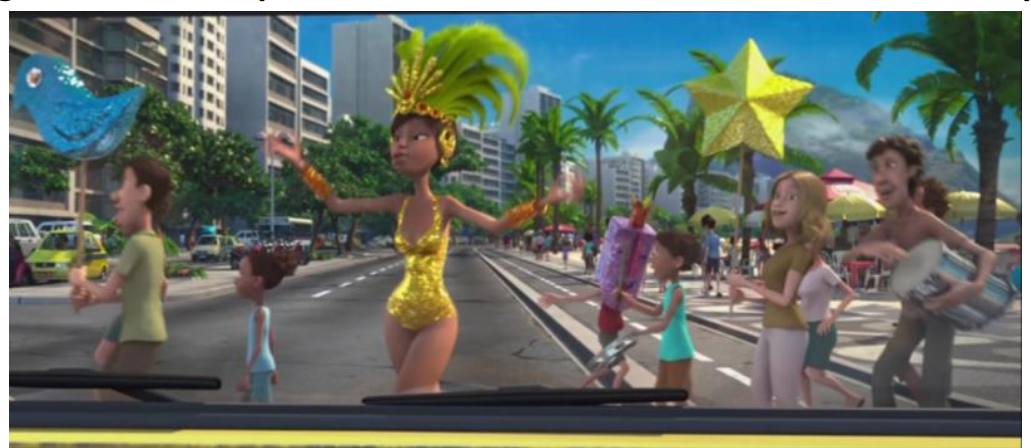

Fonte: Decupagem feita pelos autores, 2018.

Nesta outra cena vemos o garoto Fernando, morador de uma comunidade do Rio de Janeiro, recebendo do traficante Marcel pelo serviço de captura do casal de ararinhas azuis.

Figura 6: Garoto Fernando recebendo pela captura das ararinhas Jade e Blue.

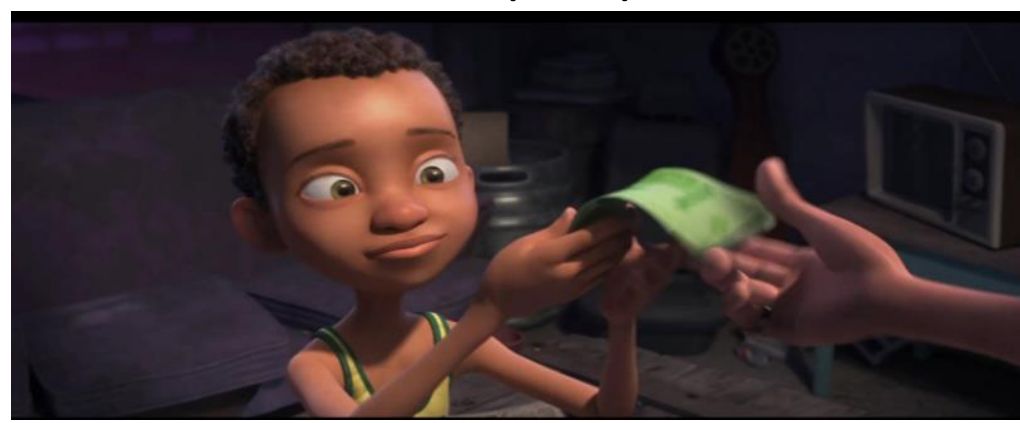

Fonte: Decupagem feita pelos autores, 2018.

Na cena antecedente, o próprio traficante Marcel relembra sobre como Fernando se parece com ele quando tinha esta idade, um garoto esperto e criativo. O traficante, confirmando sua esperteza, acaba pagando a Fernando somente a metade do combinado pela captura. O reclama com o Marcel que, sem hesitar, diz 'Cala boca, pirralho' e pede que Fernando pendure a gaiola no outro quarto. $\mathrm{O}$ garoto fica espantado com a quantidade de aves engaioladas. Ele se dirige ao casal de ararinhas se desculpando e dizendo não ser nada pessoal (ao final do filme Fernando assume para Linda que não fez por mal, mas porque precisava do dinheiro). Ao sair, Fernando olha novamente aqueles animais e se entristece, profundamente, fechando a porta.

Figura 7: Fernando sai entristecido ao ver a quantidade de aves presas naquele lugar

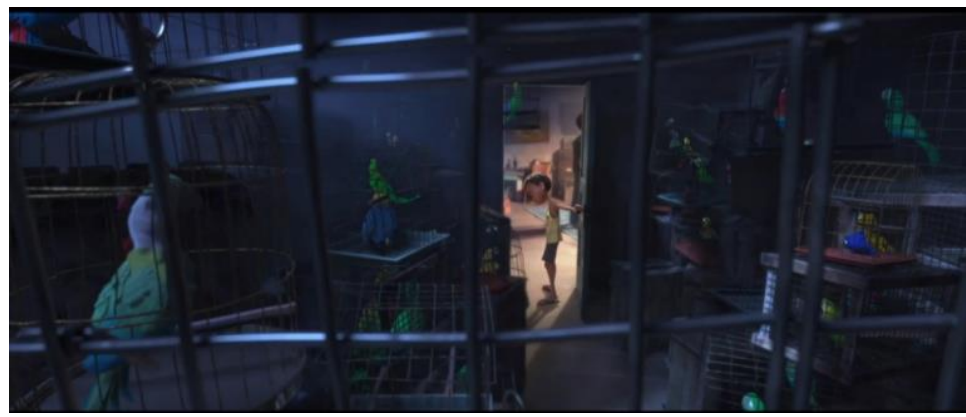

Fonte: Decupagem feita pelos autores, 2018. 
Em seguida, Fernando pergunta ao Marcel o que vão fazer com as aves e o mesmo diz que acharão uma família legal para eles e pede que Fernando vá para casa com sua mãe. Neste momento, Fernando diz não ter mãe, nem pais, nem irmãos, nem cachorro. Fernando fica mais um pouco e ouve Marcel ser questionado por outro traficante sobre o paradeiro das aves e ele responde: "Por mim podem ser depenadas, empalhadas, devorados, tô nem aí. O que importa é que vamos ficar ricos! (risos)". Vemos na fala de Marcel uma preocupação total com o lucro que ele há de ter com o tráfico das aves, não havendo nenhuma consciência ambiental de preservação daqueles animais, muitos deles ameaçados de extinção. Será que ele tinha noção do crime ambiental que ele estava cometendo? Ou, movido pela 'vontade de ficar rico', ter melhores condições de vida enxerga ali uma grande oportunidade?

Fernando vai embora e no caminho se depara com uma casa de família onde um casal canta e dança com seus filhos, ele observa pela janela e segue entristecido morro acima. Vemos na fisionomia de Fernando, uma vontade de estar com uma família, compartilhando alegrias, recebendo amor, carinho e atenção como aquela família que ele observava pela janela.

\section{Figura 8: Fernando observa pela janela uma família compartilhando momentos de alegrias}

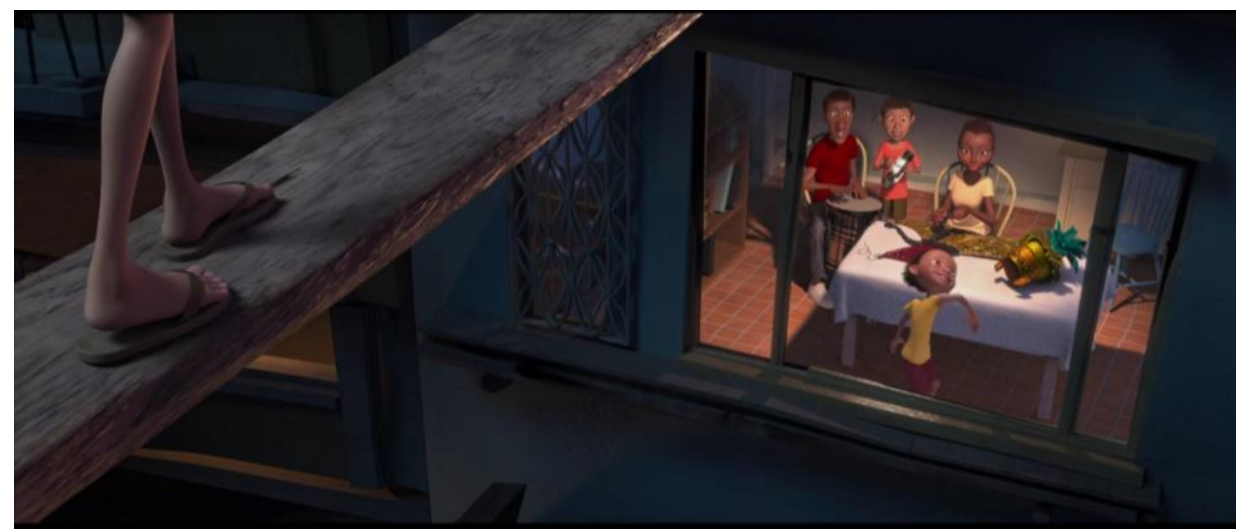

Fonte: Decupagem feita pelos autores, 2018.

Percebemos com estes trechos do filme que o garoto Fernando não é uma pessoa 'má', como, por vezes, é visto tal julgamento. Ele, assim como os outros traficantes, pode não ter escolhido, simplesmente, entrar para este universo do crime, mas, na verdade, acabaram por serem vítimas de uma sociedade injusta, desigual e que não oferece boas oportunidades para todos. Sendo ele um garoto humilde, sem família e sem qualquer amparo encontrou na criminalidade uma oportunidade de sobrevivência assim como Marcel, em um momento anterior da vida. No entanto, estas questões sociais levantadas aqui não constituem o enredo do filme, ou seja, não há um olhar crítico sobre a origem de tal criminalidade ou das exclusões e injustiças sociais. A origem de tais situações não é posta em questão sendo as cenas rápidas e superficiais ficando a cargo do telespectador fazer ou não leituras mais críticas destes contextos.

$\mathrm{Na}$ sequência, em uma das cenas mais brilhantes da animação, vemos Fernando sentado no morro da comunidade, cabisbaixo com tudo que tinha acabado de vivenciar. Ao fundo, a "cidade maravilhosa" formando um contraste com aquela comunidade. Neste momento seria possível pensar os inúmeros problemas sociais cariocas, no entanto, a animação segue apenas com um 
distanciamento da câmera sem nenhuma abordagem mais aprofundada sobre este contraste tão injusto e desigual.

Figura 9: A comunidade carioca faz contraste com a "cidade maravilhosa".

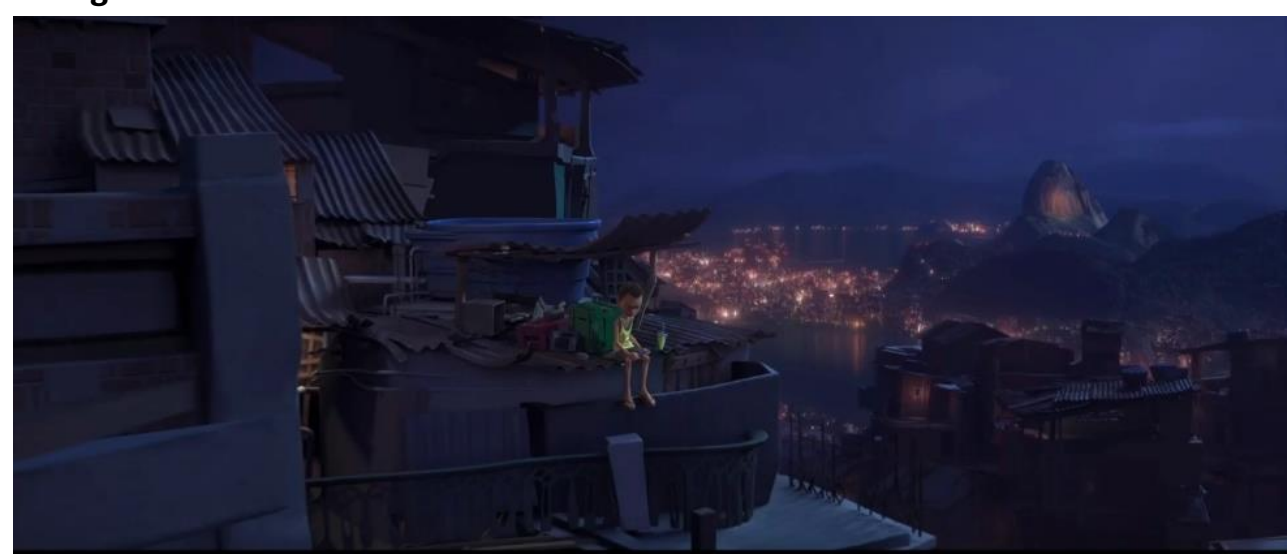

Fonte: Decupagem feita pelos autores, 2018.

A partir destas cenas pensamos ser fundamental que a realidade que produz estes sujeitos seja compreendida, o que de fato não acontece no filme. Num país de enorme extensão territorial como o Brasil onde as injustiças e exclusões sociais imperam em seus quatro cantos só é possível entender tais situações de criminalidades se os contextos sociais forem representados e discutidos de forma satisfatória, ou seja, é preciso levar em conta a história e os contextos que produziram e produzem tais exclusões e injustiças e não somente julgar, criminalizar e punir por si só.

Em consonância com Viana (2013), o histórico de crimes e violência sempre permeou a humanidade, contudo, atualmente, sociedade e governantes têm se preocupado com o seu aumento exagerado. Segundo o autor só entenderemos este fenômeno se tivermos a concepção que vivemos em uma sociedade complexa e que diversos são os fatores ocasionadores da criminalidade e violência, quais que sejam: fatores individuais, sociais, psicológicos, econômicos, coletivos, dentre outros. Desse modo, para que se consiga compreender estes fatores é necessário que tenhamos uma visão holística, ou seja, que nos lancemos sobre esse fenômeno em uma busca incessante com auxilio de diversos campos do saber, 'pois torna-se quase que desprezível falar hoje que o Direito Penal, isoladamente, não tem conseguido prevenir e combater a criminalidade, pois, essa luta há que se travar não só por governantes, mas pela sociedade como um todo' (VIANA, 2013).

Além disso, em consonância com Silva (2009), ação social dos diversos tipos de atores sociais produzem as desigualdades e exclusões sociais que, por sua vez, é estruturada pelas condições (pré)existentes das desigualdades. Segundo o autor, em consonância com a teoria marxista, as desigualdades são analisadas com base nas estruturas econômicas que, para marxistas mais recentes como Althusser, Balibar, Poulantzas, deverão ser combinadas com as (super)estruturas políticas e ideológicas. Assim, o modo de produção infraestrutural é que determina a superestrutura jurídica, político-estatal, religiosa, cultural, relevando, em última instância, o fator econômico, ou seja, para os fundadores do marxismo, a luta de classes compõe o "motor da história" e da evolução dos sucessivos modos de produção ao longo da história. O surgimento 
do modo de produção capitalista significou uma enorme libertação de servidões, vínculos presentes sob o feudalismo ao mesmo tempo em que representou a expropriação de produtores autônomos artesanais e camponeses, bem como a subsequente exploração, alienação e dominação das classes trabalhadoras pela classe burguesa (SILVA, 2009).

Por outro lado, é importante destacar as cenas onde os traficantes de aves, perseguindo o casal de araras no meio da comunidade, passam por diversos lugares em que todos estão antenados em um jogo do Brasil na final de uma copa do mundo. Em um momento seguinte, um dos traficantes interrompe a infame caçada da ararinha azul ao passar por um 'buteco' que transmitia o jogo da seleção brasileira e volta para poder assistir a jogada e vibrar pela seleção.

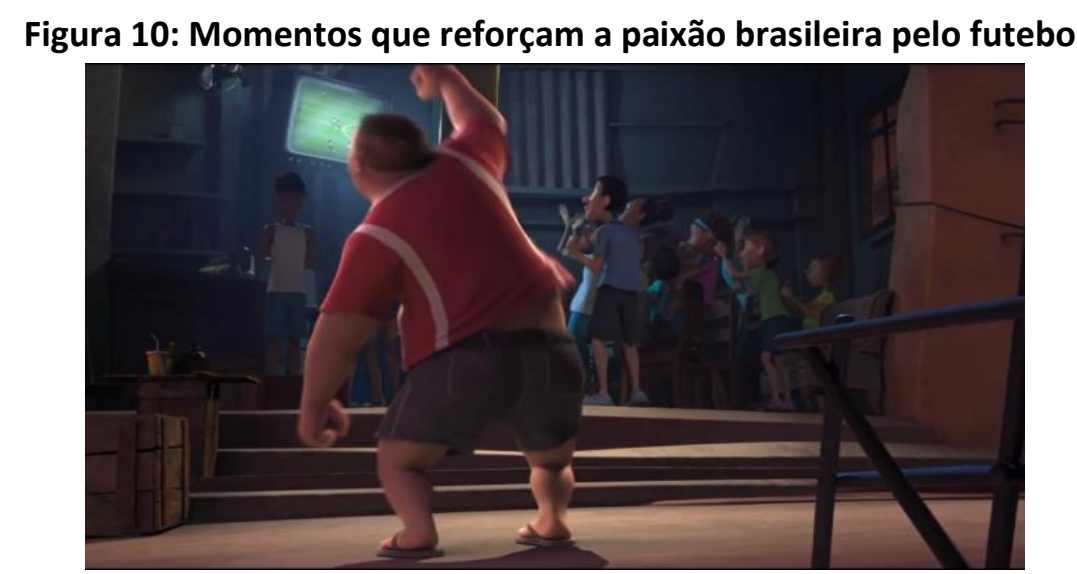

Fonte: Decupagem feita pelos autores, 2018.

Esses momentos, além de deixar explícita a paixão do brasileiro pelo futebol, mostra aos espectadores do Brasil, e do mundo, o quanto o Brasil, repleto de problemas sociais, é capaz de se unir em favor de um interesse comum quando se trata de assistir ao futebol.

Poderíamos ver esse filme como uma forma de nos orgulhar de nosso patriotismo, orgulhar de sermos brasileiro, se não fosse como coloca Paulo Lins (2014), autor do filme 'Cidade de Deus' (2002):

Ninguém está feliz no país do futebol. Não há uma família que fique tranquila com a segurança de um ente querido quando ele está na rua ou mesmo dentro de casa, seja qual for a hora do dia. Os ricos vivem em condomínios fechados cercados de guardas e circulam nas ruas com seus carros blindados numa tensão permanente. A classe média sabe que a qualquer momento alguém da família, ou mesmo um amigo, pode perder a vida num assalto. Mas a situação ainda é muito pior para os pobres das favelas e das periferias que podem ser mortos por bandidos ou pela polícia num dos países onde a polícia mata mais negros no mundo entre 15 e 25 anos, segundo várias pesquisas feitas ao longo dos anos (LINS, 2014).

Ainda em consonância com Lins (idem): 
Costuma-se colocar a culpa de toda a criminalidade no traficante de drogas, mas ninguém vira bandido de uma hora pra outra, a entrada para a criminalidade é lenta, perversa e se dá na idade escolar. Atirar na polícia não é para qualquer um. Essa disposição é pra quem sempre viveu no inferno e resolveu enfrentar o Diabo. Conheço bem traficante de drogas, pois passei boa parte da infância, juventude e maturidade ao lado deles: analfabetos, semianalfabetos, de família desorganizada, são os mais pobres entre os pobres, vistos como feios, sem direito de defesa. A punição é demasiadamente necessária assim como a recuperação dos infratores e não torná-los mais bandidos como faz o sistema penal brasileiro. A nossa organização social é que os tornam delinquentes (LINS, 2014).

Desse modo, é fundamental que tais contextos que envolvem a cidade do Rio de Janeiro e que produzem e reproduzem a criminalidade seja levado em consideração buscando um melhor entendimento de tais realidades. Isso também permitirá que maus juízos e falsos julgamentos e punições sejam repensados bem como sejam pensadas outras formas de combater a criminalidade que tem sua origem na desigualdade, nas injustiças e na exclusão. Num dos países mais desiguais do mundo, uma mulher é punida por roubar para se alimentar. E, o pior, por pessoas que também são exploradas.

Neste mesmo sentido outros estereótipos sobre o Brasil também são reforçados como, por exemplo, a cena dos macacos ostentando joias roubadas. $\mathrm{O}$ furto acontecia num dos pontos turísticos mais famosos do Rio de Janeiro, o Pão-de-Açúcar. Neste caso, um dos micos ficava responsável por distrair os turistas fazendo macaquices e os outros aproveitam para furtar seus objetos pessoais. Tais macacos são utilizados no filme como certa identificação do Brasil.

Figura 11: Macacos furtam turistas no ponto turístico do Pão-de-açúcar/RJ.

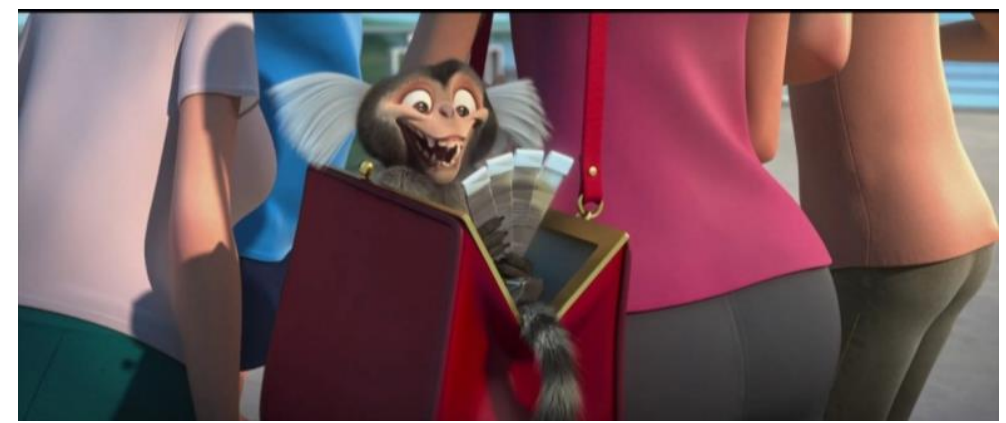

Fonte: Decupagem feita pelos autores, 2018.

Outro estereótipo seria quando estes mesmos micos invadem a festa das aves em busca do casal de ararinhas, a mando de Nagel (cacatua), e compram uma briga feia com as aves que estavam cantando e dançando em perfeita harmonia. Embora o casal de ararinhas tenha conseguido fugir, esta cena acaba passando uma imagem violenta para as crianças que, numa perspectiva da educação, pode ser problemática. Mais uma vez a ideia de um Brasil violento e agressivo, mas o que choca ainda mais é a naturalização da violência. 


\section{Figura 12: Momentos que antecedem a briga entre macacos e aves}

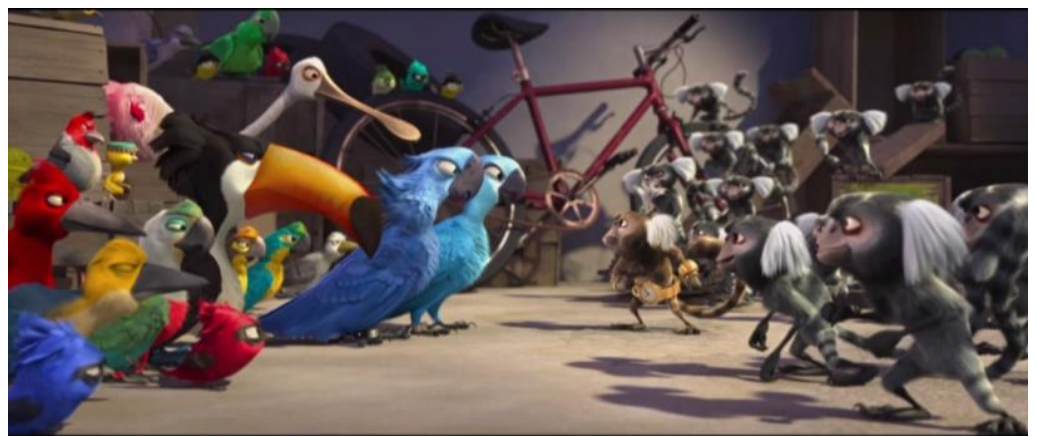

Fonte: Decupagem feita pelos autores, 2018.

É impossível negar o problema da violência no Brasil. E, ao mesmo tempo em que é necessário tomarmos consciência, de forma crítica, da nossa realidade é também vergonhoso saber que somos o país que mais se mata pessoas com armas de fogo, sendo que a cada quatro pessoas três são negras (TREVISAN, 2016). Para Ribeiro (2017) pessoas negras são utilizadas como escárnio, para serem ridicularizadas, ao mesmo tempo em que legitimam violência. Um verdadeiro descaso do país com essa parcela de brasileiros revelados por mortes anunciadas (TREVISAN, idem).

É importante destacar também que os macacos, ao se subjugarem a Nágel (cacatua) e partirem para a violência contra as aves, acabam por estarem a serviço de uma mesma lógica que também os violenta (como mostrado na cena anterior em que Nagel violenta o chefe dos macacos e os obriga a seguirem sua lógica). Ribeiro (2017) ainda acrescenta uma lógica cruel de que 'no Brasil, considerado um dos países mais desiguais do mundo, pessoas são punidas por roubar para se alimentar. E, o pior, por pessoas que também são exploradas'. Vemos, portanto, uma dupla desumanização: por viver a fome e por ser agredida por viver a fome. Neste caso, as ararinhas azuis que já viviam o drama de estarem sendo perseguidas pelos traficantes, precisavam agora escapar dos macacos que os aterrorizava. Neste caso, a coletividade das aves fez toda diferença, e a luta conjunta possibilitou a fuga de todos reforçando a ideia de que juntos podemos ser mais fortes.

Em virtude das discussões aqui apresentadas, devemos nos atentar para o fato de que o cinema é um veiculador de ideologias, posições políticas, e retrata diferentes questões da realidade dos alunos (NASCIMENTO JUNIOR et al 2016). Klammer et al. (2006) ressalta que o cinema pode ser compreendido como uma indústria cultural pensada e estruturada como uma forte ferramenta de dominação repleta de ideologias. Assim, se faz necessário que construamos um olhar crítico desses sujeitos para com as obras cinematográficas, fazendo com que esses reflitam sobre os filmes que thes são apresentados em qualquer espaço social.

Para Fantin (2007) desde a década de trinta os filmes tem sido utilizado como um recurso em salas de aula. Mas, é preciso ter cuidado, pois alguns desses trabalhos trazem uma visão na qual os alunos não são levados a olhar criticamente a tecnologia e a ciência utilizando, frequentemente, o filme apenas como um exemplo daquele conhecimento no cotidiano 
apresentando uma visão descontextualizada da ciência que não adentra nas verdadeiras dimensões sociais em que o conteúdo está inserido.

Em consonância com Nascimento Junior et. al (2016), o cinema se mostra como uma obra de arte, que vai além de recurso pedagógico, trazendo diversos problemas da realidade social dos alunos, propiciando um olhar crítico dos sujeitos para problemas presentes no seu cotidiano, fazendo assim com que eles possam questioná-la e transformá-la.

Como trazem Fresquet e Migliorin, (2015), o cinema é uma janela que nos permite olhar para o mundo, para a sociedade, para a tecnologia, para a ciência, para o ambiente, e possibilita a formação integral, cultural, científica e crítica de cidadãos.

\section{CONSIDERAÇÕES FINAIS}

A Educação Ambiental, vista na perspectiva crítica, precisa estar presente e articulada com todos os níveis de educação brasileira, de modo que permita retratar a relação entre as pessoas e o ambiente por meio de uma crítica à ordem social vigente baseada no modo de produção capitalista o qual reproduz uma sociedade injusta, excludente e que não está preocupada com as relações existentes entre questões ambientais e sociais.

Por meio deste trabalho foi possível perceber que o Filme Rio debate a ecologia, e as questões ambientais de uma maneira pouco crítica apresentando o predomínio de uma visão mais conservacionista da educação ambiental. Diante disso, uma análise mais social do filme é necessária, possibilitando utilizá-lo no ensino da educação ambiental numa perspectiva mais crítica, uma vez que esta visão tem o papel de entender o ambiente em sua totalidade, ou seja, ao pensar o ambiente é preciso que se incluam as questões políticas, econômicas, éticas, culturais e sociais. Além disso, o filme contribui para reforçar estereótipos do Brasil e do povo brasileiro que quase em nada colabora com a construção de uma visão mais crítica e emancipatória para uma educação socioambiental.

Desse modo, a visão crítica sobre as temáticas abordadas no filme acaba por ficarem mais subjetivas deixando a cargo do telespectador transpor tais questões, que pode ou não acontecer. Assim, ao não abordar de maneira crítica e histórica o ambiente da cidade do Rio de Janeiro o filme possibilita que não haja uma reflexão acerca das condições que levaram a tais situações dificultando a compreensão e transformação de tais realidades. Entretanto, pensamos que as questões aqui levantadas não impossibilitam a utilização do filme para o ensino da educação ambiental, pelo contrário, tais reflexões aqui podem contribuir para ampliar as possibilidades de abordagens das questões ambientais numa perspectiva mais crítica e emancipatória.

\section{AGRADECIMENTO}

\section{FAPEMIG e CAPES}

\section{REFERÊNCIAS BIBLIOGRÁFICAS}

BARROS, Marcelo Diniz Monteiro de; GIRASOLE, Mariana; ZANELLA, Priscilla Guimarães. O uso do cinema como estratégia pedagógica para o ensino de ciências e de biologia: o que pensam alguns professores da região metropolitana de Belo Horizonte. Revista Práxis, Volta Redonda: FOA, ano V, vo 10, 2013, p. 97-115. 
BRASIL. Lei 13.006, de 26 de junho de 2014. Disponível em: < http://www.planalto.gov.br/ccivil_03/_Ato20112014/2014/Lei/L13006.htm> Acesso em: março de 2019.

FANTIN, Mônica. Mídia - Educação e cinema na escola. Revista Teias, v.8, no 14-15, 2007.

FERREIRA, Thaís Arruda. A Importância de uma análise crítica do cinema ambiental. VI Encontro "Pesquisa em Educação Ambiental” - EPEA. A Pesquisa em Educação Ambiental e a Pós-Graduação no Brasil Ribeirão Preto, 2011.

FRESQUET, A. M.; MIGLIORIN, C. Da obrigatoriedade do cinema na escola, notas para uma reflexão sobre a lei 13006/14. Cinema e educação: a lei 13006. Reflexões, perspectivas e propostas. 1ed. Ouro Preto: UNIVERSO, 2015, v. 1, p. $4-23$.

GOMES, Mariane de Paula; MACHADO, Mônica Teixeira da Costa; MANHÃES, Ana Claudia Tavares da Silva; SANTOS, Taís de Souza, SOARES, Rosana Aparecida Ravaglia. Desenho animado: Recurso pedagógico no processo ensinoaprendizagem de educação ambiental. In: III Encontro Nacional de Ensino de Ciências da Saúde e do Ambiente Niterói/RJ, 2012.

KLAMMER, Celso Rogério; GNOATTO, Dejanira Malacarne; OZÓRIO, Érika Vanessa Kampa; SOLIERI, Mariluz. Cinema e educação: Possibilidades, limites e contradições. In: Simpósio Nacional De História Cultural. Florianópolis. 2006.

LINS, Paulo. O retrato do país do futebol [reportagem]. El País-Brasil. Junho. 2014. Disponível em: $<$ https://brasil.elpais.com/brasil/2014/05/30/politica/1401451230 721614.html> Acesso em 20/01/2019.

LISBOA, lara Alves. $\mathrm{O}$ uso do desenho animado como recurso didático- Filme Rio. Trabalho de Conclusão de Curso Licenciatura em Ciências Naturais [32f]. Universidade de Brasília. Faculdade UnB Planaltina. 2012.

MEDEIROS, Sérgio Augusto Leal. Imagens Educativas do Cinema/ Possibilidades Cinematográficas da Educação. [tese de doutorado] 2012. Programa de Pós Graduação em Educação da Universidade Federal de Juiz de Fora - MG.

NASCIMENTO JUNIOR, Antonio Fernandes; VERÍSSIMO E SILVA, Luiz Gustavo; ANDRADE, Samara Mendes Moreira. SANTOS, Ana Flavia. Vidas Secas e a formação inicial de professores: A ecologia de paisagens, a caatinga e a cultura sertaneja ganham imagem e voz na obra de Nelson Pereira dos Santos. Revista da SBEnBIO, v. 9, p. 5378-5389, 2016.

NOGUEIRA, Mara Natércia. O SAMBA: cantando a história do Brasil. In: III Concurso: Negros na Sociedade e na Cultura Brasileiras - "Construindo uma nova consciência". Centro Afro-Brasileiro de Estudos e Extensão - CEAB Universidade Católica de Goiás. 2006.

RIBEIRO, Djamila. Do estereótipo do "bem dotado" à marginalização, o Brasil do país do escárnio e da violência. [reportagem]. Carta Capital. 23 de fev. 2017.

SERRA, Glades M. Debei.; ARROIO, Agnaldo. O meio ambiente retratado em filme: Uma análise comparativa entre ficção e documentário. In: Anais do XIV Encontro Nacional de Ensino de Química (XIV ENEQ). 2008.

SILVA, Manuel Carlos. Desigualdade e exclusão social: de breve revisitação a uma síntese proteórica. Configurações. 2009, p.11-40.

SILVA, Rosana Louro Ferreira da; CAMPINA, Nilva Nunes. Concepções de educação ambiental na mídia e em práticas escolares: contribuições de uma tipologia. Pesquisa em Educação Ambiental, vol. 6, n. 1 pp. 29-46, 2011.

TOZONI-REIS, Marília Freitas de Campos. Pesquisa-ação em educação ambiental. Pesquisa em Educação Ambiental, v. 3, n. 1, p. 155-169, 2008.

TREVISAN, Maria C. O Brasil é o País que mais mata por arma de fogo no mundo? Revista Brasileiros, 25 ago. 2016.

VIANA, Isaque P. Gomes. Sociologia do Crime \& Violência: O fenômeno social e sua magnitude. Portal Educação.2013.

VYGOTSKY, Lev. Mente e Sociedade. Cambridge: Harvard University Press. 1978. 